\title{
International Oil and Gas Market Outlook
}




\section{About KAPSARC}

The King Abdullah Petroleum Studies and Research Center (KAPSARC) is a non-profit global institution dedicated to independent research into energy economics, policy, technology and the environment, across all types of energy. KAPSARC's mandate is to advance the understanding of energy challenges and opportunities facing the world today and tomorrow, through unbiased, independent, and high-caliber research for the benefit of society. KAPSARC is located in Riyadh, Saudi Arabia.

\section{Legal Notice}

(C) Copyright 2018 King Abdullah Petroleum Studies and Research Center (KAPSARC). No portion of this document may be reproduced or utilized without the proper attribution to KAPSARC. 


\section{Key Points}

he United States Energy Information Administration (EIA) and KAPSARC co-hosted an expert workshop on the international outlook for oil and gas held in Washington, D.C. on September 18, 2018. The workshop focused on the global oil and gas supply and demand equilibrium, the global liquefied natural gas (LNG) outlook, regional LNG developments, the economics of modeling oil demand, and the changing energy mix in the United States and the Kingdom of Saudi Arabia in a global context. During the one-day workshop over 50 participants from government, industry and academia examined the current status of global oil and gas markets, and forecasting and modeling methodologies, as well as future trends and likely global challenges for oil and gas markets.

Improving data forecasts for global and regional supply and demand involves transitioning from analystbased approaches to model-based approaches. A comparative analysis of long-term outlooks may provide insight into the differences between approaches.

Understanding the diversity of global energy demand forecasts requires a clear overview of electrification and climate policy adoption assumptions, as most liquids demand forecasts have so far fallen short of actual demand. Oil demand remains resilient and chemicals and transport will fuel liquids demand growth.

Future oil demand will be driven by plastics and petrochemicals. Better definitions of oil as feedstock for petrochemicals and statistics and reporting consistencies are needed to consolidate growth in crude consumption, expected to come from the petrochemicals sector.

Worldwide LNG supply and liquefaction capacity are growing. The expansion of global liquefaction capacity has led to more liquid and more commoditized LNG markets, with an increase in spot trading, and a move from oil-based to hub-based pricing.

Market coordination can help regional partners achieve energy transition goals by improving international connections through natural gas markets and regional electricity trade. 


\section{Summary}

$B$

oth global oil demand and supply are at historical peaks. The pace of growth has exceeded most analyst predictions with few signs of it slowing down. Forecasting supply and demand comes with many challenges and uncertainties. Transparency and unified definitions for hydrocarbon liquids and transitioning from analyst-based approaches to model-based approaches can help improve data forecasts. Geopolitics will always be a significant challenge to data accuracy but creating forecasting scenarios with high and low boundaries can help mitigate against shifts and surprises. Varying total energy demand forecasts requires a detailed understanding of assumptions as well as more focused research on investment decisions and responses to price and volatility cycles in oil markets.

Chemicals and transport will fuel liquids demand growth. Accelerated electric vehicle (EV) uptake, a reduction in the cost of renewables, emissions reduction in the aviation and marine industries, and more efficient use of plastics may all reduce oil demand growth. However, analysts must be wary of their forecast methodologies being influenced by policy. So far, demand growth rates have shown no signs of slowing down.

Energy use in transportation is a key part of modeling demand. It is important to note that EV adoption, policy, and other anticipated technological changes will gradually impact consumer choices and behavior and, consequently, hydrocarbon demand. The petrochemical sector is expected to be the major driver of liquids demand growth. Consolidating growth in crude consumption, expected to come from the petrochemicals sector, requires statistical and reporting consistencies.

Worldwide LNG supply and liquefaction capacity are growing. The expansion of global liquefaction capacity has led to more liquid and more commoditized LNG markets, with an increase in spot trading and a move from oil-based to hub-based pricing. LNG buyers are also opting for more shortterm spot market trades and signing shorter-term contracts.

Saudi Arabia is in a fortunate position to be able to use its oil reserves to hedge against shortages in gas supplies, but this comes at a cost. While LNG can help reduce oil consumption in the Kingdom, using it as a substitute for oil is more expensive than policies aimed at reducing oil consumption. LNG's main value is in its adaptability, scalability, and its contribution to a reduction in carbon emissions. The future of gas demand will depend on the deployment of energy efficiency measures and renewable energy generation. Varying scenarios in the prices of oil and United States' natural gas will also affect LNG export levels. Market coordination can help regional partners achieve energy transition goals by improving the connectivity of natural gas markets and regional electricity trade. 


\section{Background to the Workshop}

fter several years of oversupply, numerous energy analysts have warned of a looming supply crunch as a result of the decline in upstream oil and gas investment over the last three years. The oil industry is closer to rebalancing as the price of oil has rebounded from a low of $\$ 28$ / bbl in 2016 to a high of $\$ 80 / \mathrm{bbl}$ for Brent crude in October 2018. [Brent crude oil is currently trading closer to $\$ 60 / \mathrm{bbl}$.] The industry has proven resilient in the face of brutally low prices by improving efficiency, reducing costs and keeping prices in check, albeit with seasonal fluctuations. The volatility of the oil and gas sectors has proven challenging, and resilient strategies are needed to face the upcoming transition.

This workshop brought together key stakeholders from energy economics think tanks, government energy agencies, industry, and academia to discuss the future of oil and gas in a global context, compare and contrast modeling techniques developed mainly by KAPSARC and the Energy Information Administration, and pave the way for additional collaboration between the two organizations.

Participants discussed the following topics:

Current perspectives on the global oil supply and demand equilibrium.

The global LNG outlook and regional LNG developments.

The economics of modeling oil demand.

The changing energy mix in the United States and the Kingdom of Saudi Arabia in a global context. 


\section{Outlook for Global Oil supply and Demand}

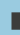

orecasting global oil supply still presents significant challenges. Bottom-up project-level and field-level analysis is the basis of most total country-level forecasts. Production profiles are integrated with field decline rates, ramp-up rates, and analyst judgment. Analyst judgment is critical in short- and medium-term forecasts outside of shale projects because project decisions are determined by companies with assumptions concerning the future price environment, cost structure, and investment cycle length. Shale projects do not fall into this category due to their shorter cycles. Analyst judgment is particularly important when determining external factors and requires more in-depth bottom-up analysis. Analysts will often take into account past performance, press coverage on announced and canceled projects, company financial reports, third-party reports, price outlook, and risks, to get a universe of projects. Analyst assumptions on final investment decisions, start dates, and price forecasts will sometimes apply. Forecasts are a combination of current production adjusted for decline rates and new production. Condensates and natural gas liquids (NGLs) are often forecast as a function of crude oil production.

Regression-based forecasting is more applicable for very small producers where little change to supply is expected in the short term. Unlike short-term forecasts, long-term oil forecasts integrate supply and demand balances rather than binary events for projects. Long-term demand forecasts vary widely depending on a number of assumptions including global economic growth, increasing electrification, improvements in internal combustion engine efficiencies, and climate policy.
The real challenges to forecasting are the political and above-ground risks. Political risk is managed in short-term supply forecasts by creating high, medium, and low production scenarios to manage possible supply shifts. Trade wars, sanctions, actual wars, natural disasters, and any number of other events can typically change the price environment. Investment decisions are also important to consider when forecasting supply.

It is important to understand net global energy demand changes before looking specifically into oil demand. Recent trends and long-term forecasts predict a significant slowdown in global energy demand growth, driven by increasing digitization and technological innovation. Increasing electrification is producing faster growth in electricity demand than fossil fuels. Views on the future of fossil fuel demand vary widely. Most experts agree that, among fossil fuels, gas is a relative winner and oil demand remains resilient. Chemicals and transport will fuel liquids demand growth. Accelerated electric vehicle (EV) uptake, a reduction in the cost of renewables, emissions reduction in the aviation and marine industries and more efficient use of plastics may all reduce oil demand growth.

Demand forecasts so far do not add up. Oil demand is still rising much faster than analysts had anticipated, partially due to an underestimation of income growth in Asia. Analyst's forecasting methodologies are often influenced by policy, which may explain some of the demand underestimations. At the moment, the futures market seems to produce the most accurate forecasts. 


\section{Modeling Oil Demand}

orecasting demand is often more difficult and problematic than forecasting supply. Oil demand forecasts are typically created using two types of modeling approaches: regression models and energy intensity models. Within these models, gross domestic product (GDP) and Brent forecasts are typically the only explanatory variables used. Short-term oil consumption forecasts are sometimes based on recent oil consumption and GDP trends, along with analyst judgment. Short-term demand is often used in a pricing model that then provides an oil price path.

Regression-based models use GDP and Brent and are then modified to get the best fit for a region. They also sometimes include other variables that reflect demand level shifts. Alternatively, energy intensitybased models use GDP to develop forecasts based on regional historical growth rates in energy intensity to forecast future consumption. Some analysts will use an average of the two models as their forecast for consumption or demand. Neither method is always accurate. Both regression and intensity models have overestimated Venezuelan and Iranian oil consumption. Unfortunately, models are limited to using variables that cannot fully capture nearterm risks, including weather, strikes, sanctions, and natural gas substitution, among others.

Transportation energy is a key part of modeling demand and the uncertainty associated with these models. Energy for transportation today is met largely by petroleum products. Technology, alternative fuels, policy, and continuing global shifts in economic activity could change future transportation energy demand, with implications for world oil and petroleum product markets. There are many issues when modeling the evolution of liquids demand in the transportation sector. Modeling transportation and freight energy demand in China and India encounters challenges such as a significant lack of available data, among other issues.
Transportation energy consumption is growing in non-Organization for Economic Cooperation and Development (OECD) countries, especially China and India, while it remains relatively flat in OECD countries. OECD nations remain important consumers of energy, and their policy changes continue to affect global energy markets. Battery EV adoption is expected to affect world liquid fuel demand gradually in the short term depending on consumer behavior and government policies. Policy and technology changes are gradual and not transformative in the medium term. The extent to which highly automated vehicles could affect future transportation energy demand remains uncertain. Widespread adoption of highly automated vehicles could also be gradual and have modest near-term effects on global liquid fuel demand.

The petrochemical sector is still a major driver of liquids demand growth. It is no secret that the United States (U.S.) is leading the development of shale and tight oil resources, spurring a renaissance in hydrocarbon production. As a result, rapid growth in natural gas plant liquids output is also occurring. Most projections currently predict NGL production growth to outpace increases in crude oil output. However, how NGLs are defined is key. Clarity and consistency on definitions are essential as specificity leads to better data, better analysis, and better projections. Natural gas plant liquids in the U.S. will contribute to an increasing share of the total petroleum supply, with the lightest molecules driving growth.

Overall it is difficult for models to explain oil price behavior because the oil market is not a 'textbook' market. Geopolitics, financial speculation and non-competitive behavior impact oil markets. Externalities like climate change concerns also impact the markets. Daily oil price volatility is very high and economic fundamentals do not always explain the surge or collapse in oil prices. 


\section{Global LNG outlook}

$\mathrm{N}$ atural gas is projected to be the fastest growing fuel among all fossil fuels. The largest increase in gas demand comes from the power and industrial sectors, with China, the Middle East, and the U.S. the centers of demand growth. Policies to substitute coal for gas to improve air quality has helped prop up LNG demand in China. Nuclear power issues in Asia have also helped propel demand even further. LNG supply developments are expanding and have been reignited due to the improving economics of pipeline and storage infrastructure, floating storage regasification units (FSRUs) or, more generally, floating liquefied natural gas. The availability of floating storage and regasification vessels helped unlock new markets where deployment of an FSRU was quicker and less expensive compared to building a full-scale onshore terminal.

Worldwide LNG liquefaction capacity is growing in the U.S., Canada, Africa, Russia, Australia, and the Mediterranean. U.S. LNG exports are expected to climb rapidly through 2020 as Asian demand grows and U.S. natural gas prices remain competitive. Historically, Asia has been the largest LNGimporting region, accounting for more than threequarters of the global LNG trade. Non-OECD Asia is expected to remain the main natural gas growth region in the long-term. Its consumption is projected to more than double, driven by environmental policies, urbanization, and strong economic growth. The majority of Asian countries will continue to rely on LNG, and to a lesser degree on pipelines, for their imports.

The expansion of global liquefaction capacity has led to more liquid and commoditized LNG markets with more spot trading. LNG is also moving away from oil-based to hub-based pricing, and LNG buyers are opting for more short-term spot market trades and signing shorter-term contracts. Flexible
LNG trade in Asia more than doubled between 2010-2017 and is projected to make up almost one half of total Asian LNG trade by 2040.

There are also interesting developments for LNG in the Middle East North Africa (MENA) region. Despite sitting on 44 percent of global gas reserves, the MENA region is becoming increasingly dependent on LNG imports as demand growth for gas outstrips supply growth. Exploration activity for indigenous gas is also underway.

Almost half of the global LNG exports in 2011 went to the MENA region. However, this share declined to 35 percent in 2017 due to competition, structural declines in gas fields, and political instability in the region.

Saudi Arabia is actively pursuing non-associated gas production. However, importing LNG could supplement domestic gas production and support oil displacement in power generation. Currently, natural gas makes up around 50 percent of Saudi Arabia's power mix, with crude oil, diesel and heavy fuel oil supplying the rest. Power demand in Saudi Arabia is increasing rapidly. The share of natural gas in power generation is also increasing, but with electricity demand growing so fast, Saudi Arabia may continue burning liquids.

The Kingdom is in a fortunate position to be able to use its oil reserves to hedge against shortages in gas supplies, but this comes at a cost. While LNG can provide a marginal benefit, using it as a substitute for oil is still an expensive option compared to policies aimed at reducing the country's oil consumption. LNG's main value is in its adaptability, scalability, and its contribution to a reduction in carbon emissions. Varying scenarios in oil and U.S. natural gas prices will also affect future LNG export levels. 


\section{The US and Saudi Arabia in a Global Context}

$\mathbf{T}$ The shale revolution over the last decade has made the U.S. the top liquids producer globally in 2017. As oil prices rise, there are still many uncertainties to U.S. shale production forecasting. U.S. onshore crude oil and natural gas production is forecast using a bottom-up well-level approach. The Energy Information Administration (EIA) uses an econometric model driven by the relationship of prices to rigs, rigs to wells, and then wells to production. Some of the key drivers for the model are prices, rig counts, production data, and analyst judgment.

The relationship between oil prices, rigs, and production from new wells is easy to understand if the drilling rate is known. One challenge is estimating the number of new wells that are coming online. Well level data typically shows long time lags ranging from one year to 18 months compared to price and production data. This causes a problem in forecasting the number of wells and capturing the signals to drill and complete a well. A hyperbolic decline curve is fitted to wells drilled in the past and extended throughout the forecast period (48 months). Production from new wells is forecast using an econometric model.

Four different types of price predictors are used in the EIA's model: West Texas Intermediate (WTI) Cushing, WTI Midland, Henry Hub, and Appalachian spot prices. Production generally correlates to price with a six-month lag, price correlates to rig count with a four-month lag, and rig count to production with a two-month lag. A rig efficiency factor, or an assumption of the number of wells per rig, is used to estimate how many new wells will be drilled overall. Six months of historical well data are used to get the estimated ultimate recovery (EUR). Unlike rigs, it is more challenging to forecast wells directly due to well data lags.
Production data and analyst judgment are used to make an assumption of the number of wells needed to maintain production at this level, based on the EUR and well data for the region. This also helps determine the number of wells needed per rig to maintain production.

While this rig-efficiency methodology gives accurate estimates of well completions, this is still an area that needs further improvement. It would be useful to capture the month-to-month variability of completions that could come from different types of price signals, especially since the short-term model is a monthly model. It is important to note that the decision to complete a well can vary from company to company.

When discussing Saudi Arabia's energy transition, four things are important to note: the change in domestic energy sources, growth in natural gas, plans for renewable energy supply growth, and the changing structure of domestic energy prices. These efforts are aimed at reducing and optimizing consumer subsidies and helping industrial sectors transition away from their reliance on primary energy exports. Saudi Arabia proposed plans such as pricing incentives to increase fuel efficiency, incentivizing local manufacturing of goods and increasing local content.

KAPSARC has studied the impact of fuel price reforms on Saudi Arabia's total energy consumption and found that the Kingdom could reduce energy use by more than 2 million barrels of oil equivalent per day in the medium-term. Other research has shown that market coordination can also help regional partners achieve their energy transition goals by improving connections through natural gas markets or regional electricity trade. So far, the Gulf Cooperation Council Interconnector 
is not used to its full potential partially due to fuel subsidies, which are impeding the willingness of member states to participate and realize the benefits of electricity trading. Other plans to connect electric grids in Saudi Arabia to North Africa and possibly Turkey, to alleviate the excess of renewable energy technology on the horizon, are currently being studied.
Fuel price reforms are expected to displace much of the oil used in Saudi Arabia and will free it up for export markets. This will have an immediate impact on the role of Saudi Arabia as a crude supplier. Currently, there are initiatives in the Kingdom to study future areas of oil use, such as crude-tochemicals and different modes of transportation. 


\section{About the Workshop}

his workshop took place in Washington, D.C. on September 18, 2018. It brought together 50 international experts to discuss the future of oil and gas, with a significant EIA and KAPSARC presence. There was a special focus on forecasting methodologies for supply and demand using different models and an analysis of LNG in the global context.

\section{List of participants}

Atul Arya - Senior Vice President, IHS Markit

Sian Bradley - Research Associate, Chatham House

Michael Browne - Economist, International Finance Corporation (IFC)

Gianni Di Giovanni - Chairman, Eni Petroleum Co Inc.

Gina Erickson - Desk Officer for Saudi Arabia, Department of Energy

Dean Foreman - Chief Economist, American Petroleum Institute (API)

Steven Gabriel - Professor, University of Maryland

Fuad Hasanov - Senior Economist, International Monetary Fund (IMF)

Horace Hobbs - Chief Economist Corporate Strategy, Phillips 66

Hasashi Hoshi - Board Member in charge of Oil \& Gas, Institute of Energy Economics, Japan (IEEJ)

Henrik Jeppesen - Head of Investor Outreach North America, Carbon Tracker

Fred Joutz - Professor and Co-Director of Research Program on Forecasting, The George Washington University

Tae-Yoon Kim - WEO Team, International Energy Agency (IEA)
Eric Lee - Energy Strategist, Citi Research

Jane Nakano - Senior Fellow, Energy and National Security Program, Center for Strategic \& International Studies (CSIS)

Richard Newell - President, Resources for the Future

Matt Partridge - Head of Market Analysis, North America, Equinor ASA

Aldo Spanjer - Pricing \& Supply Advisor, Shell Energy - Global Integration

Christer Tryggestad - Senior Partner, Global Energy Perspectives, McKinsey \& Company

David Victor - Professor, School of Global Policy and Strategy

\section{EIA}

Vipin Arora - EIA

Linda Capuano - Administrator, EIA

Nicholas Chase - Industry Economist, EIA

David Daniels - Chief Energy Modeler, EIA

Rebecca George - Operations Research Analyst, EIA

Peter Gross - Analyst, EIA

Tim Hess - EIA

Angelina LaRose - Director of the Office of Integrated and International Energy Analysis, EIA

Thomas Lee - Economist, Markets \& Financial Analysis Team, EIA

Danya Murali - Mathematical Statistician, EIA 
lan Mead - Assistant Administrator for Energy Analysis, Carol Cormack - Workshop Coordinator, KAPSARC EIA

Jim Turnure - Director of the Office of Energy Consumption and Efficiency Analysis, EIA

Warren Wilczewski - Industry Economist, EIA

\section{KAPSARC}

Shahd AIRashed - Research Associate, KAPSARC

Firas Barazi - Senior Advisor, KAPSARC Advisory Services

Jorge Blazquez - Research Fellow, KAPSARC
David Hobbs - Former Vice President of Research, KAPSARC

Bert Rioux - Research Fellow, KAPSARC

Rami Shabaneh - Research Associate, KAPSARC

Adam Sieminski - President, KAPSARC

Colin Ward - Research Fellow, KAPSARC

Kang Wu - Program Director, KAPSARC 
Notes






\section{Notes}

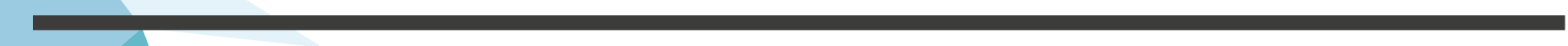




\section{About the Team}



\section{Shahd Alrashed}

Shahd is a research associate in the Markets and Industrial Development program. She previously worked at Chevron as a flare and relief systems engineer and a facilities engineer supporting upstream and downstream facilities worldwide based in Houston. Shahd holds a master's degree in mechanical engineering with a focus on advanced energy systems from UC Berkeley and a B.S. degree in mechanical engineering from Boston University.



\section{Colin Ward}

Colin is a research fellow in KAPSARC's Markets and Industrial Development program primarily focusing on cost estimation for energy projects and environmental impacts of the global energy industry. He holds an MBA from the University of Texas, a B.S. degree in electrical engineering from the University of Houston, and a B.A. degree in philosophy from Tulane University.

\section{About the Project}

The project is part of an ongoing analysis into global oil supply and investment behavior, and responsiveness to oil prices. The purpose of the study is to analyze the projected outlook for global crude oil and other hydrocarbon liquids supply from 2018 to 2022 based on various price scenarios. Historical investment and supply responses to oil price changes are also examined with an emphasis on the 2008 and 2014 oil price crashes. 
INAPSARC



www.kapsarc.org 